\title{
EL NEGRO EN EL CINE DE ARGENTINA, BRASIL Y CUBA
}

\author{
Victor Manuel Amar Rodriguez \\ Doctor em Historia del Arte por la Universidad de Sevilla (España), especialista en cine latinoamericano.
}

RESUMO: Este artigo tem como objetivo abordar a imagem do negro no cinema argentino, brasileiro e cubano. Do ponto de vista europeu, o cinema latino-americano é freqüentemente encarado como algo distante, a despeito dos laços culturais e históricos que nos unem. Essa distância torna-se ainda maior quando os filmes sāo dirigidos e estrelados por negros, ou quando tratam de sua cultura. O cinema deve relacionar-se com a realidade e seu desenvolvimento depende do estudo e representação da mesma. Nossa atenção, portanto, volta-se para o negro e sua contribuiçāo/valorização cinematográfica.

ABSTRACT: This article's objetive is to discuss the image of the "black" in the Argentine, Brazilian, and Cuban cinema. From a European viewpoint, Latin American cinema is generally regarded as something distant, despite their cultural and historical ties. This gap is widened when the movies are directed and starred by "negros", or when such movies depict the "negro" culture. The cinema must convey reality and its development depends on the study and representation of the latter. Therefore, our attention is focused toward the negro and his cinematographical contribution and appreciation.

PALAVRAS-CHAVE: Negro, Cinema, América Latina, História da Cultura, História Contemporânea.

KEY-WORDS: "Negro", Cinema, Latin America, History of Culture, Contemporary History.

\begin{abstract}
Los dioses africanos continuaban vivos entre los esclavas de Amtérica corno vivas continuaban, alimentadas por la nostalgia, las leyendas y los mitos de la patrias perdidas.
\end{abstract}

GALEANO, 1988, p. 164

Atendiendo a la configuración del mapa etnográfico-racial de América Latina, el Negro se "esta- bleció" en las tierras bañadas por el ocêano Atlántico hasta la desembocadura del Río de la Plata, en las Antillas y puntos de México y mezoamérica, además de comarcas muy concretas en la costa del pacífico.

El primer país que pasamos a focalizar es Argentina; una nación eminentemente de ascendencia latinoeuropea, no obstante, resulta paradójico encontrar en el panorama filmográfico a un director de 
cine mulato (padre blanco y madre negra), como es el caso de José Agustín Ferreyra.

Escasos son los ejemplos existentes dentro del cineargentino en que encontraremos películas con una temática, directores y/o actores negros... así que, ésto podría ser entendido cn la medida que la realidad multiracial al pueblo argentino le quedaba un poco distante.

El 18 de julio de 1896 llega el cine a la Argentina, concretamente al teatro Odeón de Buenos Aires, con cintas como La Llegada de un Tren a la Estación de la Ciotal, Salida delos Obreros de la Fabrica Lumière. Sin embargo, se considera la primera película argentina la realizada por el francés Eugène Py, titulada La Bandera Argentina (1897). Prácticamente con el surgir del cine nacional, nace un joven que más tarde se convertirá en pieza clave para el desarrollo del cine argentino de décadas posteriores. Nos referimos a Jose A. Ferreyra (18891943), pintor, músico, escenógrafo y, sobre todo, hombre de cine; apodado y conocido en el mundo del celuloide como el negro, aspecto que hacía alusión al tono oscuro de su piel. Su filmografía cabría dividirla en dos períodos: a) Silente, iniciándolo en 1915 con el cortometraje Una Noche de Garufa y continuándola con cintas tan significativa como $E l$ Ultimo Tango (1925), o bien, Perdón Viejita (1927), entre otras. b) Sonoro, tras un viaje a Europa, Estados Unidos y al resto de América Latina... y un hecho relevante en la historia del cine como fue la irrupción del sonoro con la película El Cantor de Jazz (1927), con la voz y la cara pintada del actor Al Jolson, sincronizada por el sistema Vitaphone; invento que se extendió por todo el mundo. Dentro de estos años de euforia e inovación, Ferreyra intuyó las posibilidades que existirían en sumarle a la magia de las "sombras" en movimiento, el sonido. Se sucedieron varios intentos por parte de otros directores argentinos, valga el ejemplo de Roberto Guidi, Luis Moglia Barth... a los que habría que aunarle la experiencia de Ferreyra adquirida en cintas como Muñequita Porteña (1931), título original que a consecuencia de un lapsus calami se divulgó equivocadamente como Muñequitas Porteñas. Seguidamente otros directores continuaron dinamizando el cine criollo hasta constituirlo en el cine más importante de América Latina de habla hispana; resultaría injusto no hacer mención a Angel Mentasti, Mario Soffici, etc., al tango, a Libertad Lamarque o Carlos Gardel.

Retomando de nuevo a nuestro director, Ferreyra es considerado por la mayoría de los investigadores y estudiosos como el creador del cine argentino como arte, adcmás de vivir siempre de cara a la realidad de su Argentina natal, envuclto en un sentimiento populista de la vida. Su cine se caracterizó por un estilo ágil y de fácil conexión con el universo porteño y sus gentes. Cabría finalizar este apartado reproduciendo parte de un texto escrito por Estela dos Santos, en el cual se pone de relieve la importancia de Ferreyra dentro del panorama cinematográfico argentino:

Ferreyra es el primer director, y por muchos años el único que con su nombre como garantía lleva público a las salas sin actuar en la pantalla. Como se dice hoy "una película de Antonioni o de Bergman", en los años veinte se decia por estos lares "es una de Ferreyra", con abstracción de los actores, que eran muñecos dóciles del director creador. Una manera autoral de hacer cine, que en la Argentina no tuvo continuadores hasta épocas muy recientes. Ferreyra ponía a todo el equipo al servicio de su idea: solo al final de su vida, despúes de crear el mito cinematográfico de Libertad Lamarque, supeditó sus películas a la estrella que se lo fagocitó. (SANTOS, 1971, p. 27)

A continuación nos detendremos a analizar el panorama cinematográfico en el Brasil, en relación al negro en el cine de este "subcontinente de lengua portuguesa" de América del Sur. Desde sus orígenes comprobamos que el negro existió en su filmografía, no obstante, fue a partir del movimiento Cinema 
Novo cuando tomó un tratamiento más de acuerdo y comprometido con la realidad, eludiendo el folclorismo, lo anecdótico.

El actor negro Benjamín de Oliveira, durante años fue la principal atracción de uno de los más conocidos circos, el circo Spinelli, de Río de Janeiro, en los primeros años del recién iniciado siglo XX. A partir de su experiencia circense y pantomimas, en 1908 le proponen interpretar en calidad de actor principal, el papel de Peri, en el cortometraje Os Guaranis (1908) dirigido por el también fotógrafo Antonio Leal e inspirado en la novela homónima de José de Alencar. La producción corrió a cargo de dos de los más prestigiosos productores del momentos: Labanca y Leal \& Cia. Asimismo, el elenco estuvo compuesto por algunos miembros de la troupe del circo Spinelli, además de contar con la participación de la actriz Inês Cruzetta. Esta película cabría considerarla la primera adaptación de una novela al cine brasileño, a pesar de que en el apartado técnico la câmara todavía no se había librado del todo de su emplazamiento fijo, además de filmarse sin decupar. Sin embargo, se convirtió en un éxito en taquilla.

Antes de finalizar la década, uno de los cantantes negros más populares de estos años, el polifacético Eduardo das Neves, interpretó dos películas cantadas: $O$ Pronto, que cosechó un relativo éxito de taquilla y de la crítica; y el drama Sangue Espanhol, producida por el cspañol establecido en São Paulo y, más tarde, en Rio de Janeiro, el valenciano Francisco Serrador:

El cine Brasil presentó la película cantada Sangue Es. panhol, bellísima cinta dramática cantada e imitada por el conocido cantante Eduardo das Neves. Es decir, la cinta es estranjera, pero quien estaba detrás de la pantalla, cantando y declamando, era Dudu das Neves. (ARAUJO, 1976, p. 309)'

1. Vicente de Paula Araújo. A Bcla Época do Cinema Brasilciro. São Paulo, Perspectiva, 1976.

"O cinema Brasil apresentou o filme cantante Sangue
Este tipo de espectáculo sin precedentes en el Brasil, filmes musicales (a la magia visual del cine habría que sumarle la voz y la música de actores y músicos que cantaban y tocaban detrás de la pantalla), inspirados en operetas y temas del carnaval, tuvieron gran relevancia en la fase embrionaria y posterior desarrollo de uno de los géneros más característicos del cine del Brasil: La Chanchada (film musical carnavalesco, que registró un considerable éxito en los años 40 y 50).

Con el advenimiento del sonoro, el cine en el Brasil continuó madurando e intentando encontrar una "fórmula" que se identificara con el pueblo, no conectando tanto con el análisis de la realidad sino, más bien, con la manera de sentir y divertirse de sus gentes. En cste sentido cabría contemplar a la chanchada, un género genuinamente carioca, que aglutinó la mayoria de la producción del país durante prácticamente dos décadas. En este contexto habría que atender a otro gran actor negro, Grande Otelo, aunque nació en el estado de Minas Gerais, siempre se sintió carioca de adopción. Sus comienzos en el universo del espectáculo fueron como actor de teatro $y$, poco apoco, fue introduciéndose en el mundo del celuloide. Grande Otelo poseía un sinnúmero de características innatas y adquiridas que lo harían convertirse en uno de los actores más queridos del Brasil. En su carrera trabajó al lado de los más prestigiosos directores del momento (José Carlos Burlé, Watson Macedo...) y junto a los más entranables cómicos del país (Zé Trinidade, Mesquitinha...), pero fue al lado del actor de origen español, Oscarito, con quien cosechó los exitos más inusitados. Sin duda alguna, escribió una de las páginas más memorables del cine de este país.

Espannol, 'belíssima fita dramática cantada e imitada pelo conhecido cançonetista Eduardo das Neves'. Quer dizer, a fita era estrangej$\mathrm{ra}$, mas quem ficava atrís do pano, cantando e declamando, èra Dudu das Neves." 
Una mención aparte debemos hacer a la cinta Sinha Moça (1953) dirigida por Tom Payne, inspirada en el libro homónimo de Maria Dexonne y Macheco Fernades, con producción de la Compañia Cinematográfica Vera Cruz (São Paulo). Esta compañía se preocupó por realizar un cine de imitación (europco), mercantilista y soslayó la realidad del Brasil. Volviendo de nuevo a esta película añadiremos que focaliza uno de los momentos de la historia contemporánea del Brasil más significativos, como fue cl fin de la esclavitud - La Ley Aurca.

Retomando a estc actor, Grande Otelo, podemos introducirnos en la siguiente década, los años 60, y por tanto, uno de los períodos más representativos para el cine nacional; nos referimos concretamente a) Cinema Novo, que disfrutaría durante esta década y parte de la siguiente de sus mejores elogios y, paulatinamente, se fue diluyendo a partir del golpe militar de 1968.

Desde las primeras realizaciones cinemanovistas, Grande Otelo estuvo vinculado al movimiento cinematográfico. Lo podríamos recordar por su extraordinaria interpretación como Espíritu da Luz Soares, aquel pobre compositor de sambas que es fruto de las injusticias y los engaños, experimentando una de las sensaciones más amargas de un hombre consagrado a la música, ver plagiadas sus composiciones. Nos referimos a la cinta Rio, Zona Norte (1.957) de Nelson Pereira dos Santos; o bien, algunos años más tarde le volvemos a ver en una de las películas más emblemáticas del Cinema Novo (fase de cine-metáfora), concretamente en Macunaima (1969), como el Macunaíma negro, de Joaquim Pedro de Andrade.

No obstante, fue con el Cinema Novo cuando el negro tuvo peso específico en el cine del Brasil, no sólo como actor: Luiza Maranhāo (la Sofía Loren en negativo, o bien, la Venus de Ebano, como muchos críticos la llamaron cariñosamente), Elizer Gomes, Lídio Silva... y Antonio Pitanga, uno de los actores más importantes de lo que podríamos llamar el ciclo de cine bahiano (Barravento, A Grande Feira...) y del cinema novo carioca (Ganga Zumba, A Grande Cidade...), con una trayectoria de actor que se continúa hasta la actualidad; además mención obligada es su actividad como director en la película Na Boca do Mundo (1978) co-intepretada al lado de una de las divas más importantes del cine brasileño: Norma Benguell.

También en relación a la temática el movimiento cinemanovista tuvo presente al negro, que hasta prácticamente estos años había registrado un enfoque frívolo de la realidad en que se encontraba inmerso este colectivo que representa un importante sector de la población del Brasil. Esta problemática se aborda desde la perspectiva del documental Aruanda (1960) del director paraibano Linduarte Noronha, hasta el enfoque ofrecido por las ficciones Barravento (1960) del bahiano Glauber Rocha, Bahia de Todos os Santos (1961) del paulista Triguerinho Neto, Ganga Zunga, O Rei dos Palmares (1964) del carioca, de origen alagoano, Carlos Diegues.

Añadiremos la intervención, cada vez más común, de artistas negros como protagonistas (Grande Otelo, Luiza Maranhāo, Antonio Pitanga, Elizer Gomes...), además de la utilización del "negro" como contenido de las películas. (AMAR RODRIGUEZ, 1994, p. 209)

Este mayor acercamicnto al negro ya se atisbó en las comunicaciones presentadas en el I y II Congreso Paulista de Cine y en el I Congreso Nacional de Cine Brasileño, todas ellas en la primera mitad de la década de los 50. Estas enseñanzas fueron recuperadas y restablecidas por los cinemanovistas, sobre todo con Glauber Rocha, Nelson Pereira dos Santos, Carlos Diegues, entre otros.

[...] alguien se puede preguntar ¿dónde buscaremos las historias de contenidos nacionales? Las fuentes para esto son inagotables. Basta recordar que contamos con una literatura riquísima, un folclore con tres pilares - portugués, 
indigena y africano - y una historia seductora, llena de pcqueños y de grandes acontecimientos. (DOS SANTOS, 1952, sin/paginar) ${ }^{2}$

En las décadas de los 70 y 80 , obviamente continuaron realizandose películas que contaron como eje argumental al negro, solo por citar algunas: $O$ Amuleto de Ogum (1975) de Nelson Pereira dos Santos, Xica da Silva (1976) de Carlos Diegues; Tenda dos Milagres (1977) de Nelson Pereira dos Santos; Pedro Mico (1985) de Ipojuca Pontes, que contó como actor principal con Pelé; Jubiabá (1986-87) también del director paulista afincado en Rio de Janeiro, Nelson Pereira dos Santos, basada en la novela homónima del escritor bahiano Jorge Amado.

Jubiabá de Nelson Pereira dos Santos es la historia de un gran amor entre una joven blanca y loca, Lindinalva (Françoise Goussard) y el negro Antônio Balduíno. La política pasa casi desapercibida, apenas en el final. No obstante, en el libro de Jorge Amado, la parte de las luchas políticas es tan importante como la amorosa. $Y$ la cuestión racial, que años después el escritor volvería a disculir más profundamente en Tendas dos Milagres, está bastante presente también. Por necesidad de la adaptación, Nelson se centró más en la relación amorosa. $O$, talvez, en función de su estado anímico, haya preferido priviligiar el placer estético del cine - a través del amor - a la discusión ideológica. Porque en la adaptción de Tenda dos Milagres priorizó lo contrário. (SALEM, 1987, p. 348)

2. I Congreso Paulistn del Cine Brasileño. São Paulo. Abril. 1952. Tesis presentada por Nelson Pereira dos Santos, titulada: "O Problema do Conteúdo no Cinema Brasileiro". Sin paginar.

"[...] alguém pode perguntar, onde procuraremos as histórias de conteudos nacionais? As fontes para isto são inesgotáveis. Basta lembrar que contamos con uma literatura riquísima, um folklore con três pilares - portugues, indigena e africano - e, uma história sedutora, chcia de pequenos e de grandes acontecimentos."

3. Helena Salem. Nelson Pcrcira dos Santos: O Sonho Possivel do Cincma Brasilciro. Rio de Janeiro, Nova Fronteira, 1987.

"O Jubiabá de Nelson Pereira dos Santos é a história de um grande amor entre uma jovem branca e loura, Lindinalva (Françoise Goussard) e o negro António Balduino. A política passa de raspāo, apenas no final. Mas no livro de Jorge Amado, a parte das lutas políticas é igualmente importante à amorosa. E a questāo racial, que anos depois o escritor voltaria a discutir mais profunda-
Otra cinta también importante de estos últimos años de la década de los 80 fue Natal da Portela (1988) de Paulo Cesar Saraceni, un film biográfico que en 90 minutos narra la vida de uno de los hombres más emblemáticos del carnaval carioca. Asimismo, para concluir este apartado, hagamos sólo mención a la producción de pornochanchadas, (una derivación un tanto especial de la original chanchada), donde el apartado estético brilló por su ausencia.

Por último, nos detendremos en la cinematografía de Cuba, otro país de América Latina que posee una dilatada $\mathrm{c}$ interesante historia del cinc, que arranca con la primera sesión pública llevada a cabo en La Habana el 24 de enero de 1897. Desde este mágico momento se han realizado muchas películas en Cuba (por cubanos y extranjeros); pero existe un hecho histórico que podría servirnos para establecer dos momentos en la cinematográfia de este país caribeño, que se corresponde con el antes y el después de la Revolución de 1.959. Por todos es conocido aquellos años en que esta isla antillana era un apéndice de los Estados Unidos, no solo en lo que concerniente a lo político, sino también en lo cultural. Su producción cinenatográfica estaba ciertamente determinada por su vecino del norte, que controlaba los mecanismos de distribución en la isla, además de imponer los gustos, dejando el cine como un órgano exclusivo para el divertimento.

Tras la victoria de la Revolución castrista, la cinematográfia cubana experimentó una nueva evolución: "en Cuba debemos hablar del cine que se venía realizando tras la revolución donde, por un lado, el ICAIC (productora, distribuidora y exhibi-

mente em Tenda dos Milagres, está bastante presente também. Por necessidades da adaptaçăo, Nelson se concentrou na relação de amor. Ou, talvez, em função do próprio momento dele, tenha preferido privilegiar o prazer estético do cinema - através do amor - à discussāo ideológica. Porque na adaptação de Tenda, ele percorreu justo o caminho inverso." 
dora de películas cubanas) había adquirido una gran importancia y, por el otro, los nuevos directores centraban su temática en asuntos relacionados con la reconstrucción del país y el triunfo de la revolución […]". (AMAR RODRÍGUEZ, 1992, p. 84)

Dentro de este contexto post-revolucionario, el negro en calidad de actor (Julio Hernández, Tete Vergara...), de director (Sara Gómez, Sergio Giral), o bien, de temática (La Ultima Cena, 1976, de Tomás Gutiérrez Alea, sobre la esclavitud de los negros de Cuba en las plantaciones de azúcar en el siglo XVIII, las relaciones con los blancos, la ansia da libertad...), adquieren un mayor protagonismo convertiéndose en un elcmento integrado en cl proceso artístico-creativo, y abandonándose progresivamente aquel tratamiento cómico-domésticomarginal que sufrieron durante las décadas anteriores.

Volviendo de nuevo sobre el apartado de los directores, que en el párrafo anterior sólo habíamos esbozado, añadir que la habanera Sara Gómez (1943-1974) fue la primera y única mujer cubana en realizar un largomctraje, De Cierta Manera (además de ser el primer largometraje de ficción filmado en $16 \mathrm{~mm}$.). Asimismo, se inició en el documental en 1964 Irá a Santiago y realizó otros tan emblemáticos como Excursión a Vueltabajo (1965), A tención prenatal Año Uno (1972), Sobre Horas Extras y Trabajos Voluntario (1973). A propósito de su largometraje titulado De Cierta Manera (1974), cabría añadir que es una radiografía con una clara intención de análisis a la sociedad cubana, en relación a la mujer, no sólo como individuo sino también tenien. do presente su proyección en la sociedad, apuntando las causas y consecuencias. Desgraciadamente la cinta no pudo ser acabada por la directora, ya que la muerte la sorprendió (una fuerte crisis asmática) mientras la finalizaba. Sus amigos y también directores de cine, Tomás Gutiérrez Alea y Julio García Espinosa, quienes habían acompañado el proceso, además de haber la aconscjado en determinados momentos, fueron los encargados de terminarla. "La única película cubana hecha por una mujer y sobre el tema de la mujer, resultó ser la gran obra maestra de los años setenta en este país". (SCHUMANN, 1987 , p. 170).

En torno a Sergio Giral comentarles que aunque nació cn La Habana en 1937, pasó un periodo de su vida en Nueva York, regresando a la isla en 1958 y tras la Revolución formó parte del ICAIC en calidad de productor. Igualmente fue director iniciando su actividad a partir de 1962 con la cinta Henificación y Ensilaje, y que continuó, a film por año, hasta que realizó El Otro Francisco (1975), abordando la sociedad esclavista; posteriormentc llevó a cabo Rancheador (1977) y Maluala (1979).

En rclación al actor en Cuba cabría añadir que este mantuvo una buena relación con el cine realizado en la isla, al menos tras el triunfo de la revolución. No obstante, el actor negro profcsional escaseo, sin embargo, el proceso de integración de éste en el panorama cinematografico fue cada vez mayor. $\mathrm{Al}$ respecto el propio Tomás Gutiérrez Alea en una entrevista concedida a la investigadora y periodista argentina Silvia Orozas así lo comenta:

En general no hay actores suficientes, pero negros faltan aún más que blancos [...]. Dar vida a los persojanes con este tipo de actor es lo más difícil, y hay siempre pro. blemas de disciplina, por desconocimiento del trabajo. (OROZ, 1985, pp. 147-148)

En resumidas cuentas csto ha sido, de forma muy genérica, un acercamiento a la historia del cine de América Latina que ha tenido, de una u otra manera,

4. Silvia Oroz. Guticrrcz Alca: Os Filmes que nâo Filmci. Rio de Janeiro, Anima, 1985

"Em geral nāo há atores suficientes, mas negros faltam ainda mais do que brancos [...]. Dar vida aos personagens com esse tipo de ator é o mais difícil de tudo, e há sempre problemas de disciplina, por desconhecimento do trabalho." 
presente al negro. Un negro que fue "llevado" al continente americano por intereses y que ahora convive con el resto de sus coterráneos aunque, desgraciada-

\section{Bibliografia}

AMAR RODR ÍGUEZ, Victor Manuel. El Cine cn Amćrica Latina. XXIV Muestra Cinematográfica del Atlántico de Cádiz, 1992, pp. $81-88$.

El Cinc Nucvo Brasileño (1954-1974). Madrid, Dykinson, 1994.

ARAUJO, Vicente de Paula. A Bcla Epoca do Cincma Brasileiro. Sāo Pauilo, Perspectiva, 1976.

GALEANO, Eduardo. Las Venas Abiertas de America Latina. Madri, Siglo XXI, 1988. mente, la pobreza, la discriminación, la dicotomia social, las enfermedades, la falta de recursos... todavía tienen color.

OROZ, Silvia. Guticrrez Alea: Os Filmes que nāo Filmei. Rio de Janeiro, Anima, 1985.

SALEM, Helena. Nelson Percira dos Santos: O Sonho Possivel do Cinema Brasileiro. Rio de Janeiro, Nova Fronteira, 1987.

SANTOS, Estela dos. El Cine Nacional. Buenos Aires, Centro Editorial de América Latina S.A., 1971.

SCHUMANN, Peter B. Historia del Cine Latinoamericano. Buenos Aires, Legasa S.A., 1987. 